\title{
Monitoring of JUICE optical fibers during thermal cycles keeping the optical connectors at different stable temperatures in 3-chambers setup
}

J. Barbero, I. Jernej, C. Hagen, W. Magnes, R.

Lammegger, et al.

J. Barbero, I. Jernej, C. Hagen, W. Magnes, R. Lammegger, A. Betzler, C. Amtmann, M. Faust, A. Hauser, T. Schirmann, S. Mariojouls, A. Salomon, V. Lelievre, I. Torralba, I. McKenzie, "Monitoring of JUICE optical fibers during thermal cycles keeping the optical connectors at different stable temperatures in 3-chambers setup," Proc. SPIE 11852, International Conference on Space Optics - ICSO 2020, 118522S (11 June 2021); doi: 10.1117/12.2599449

SPIE Event: International Conference on Space Optics - ICSO 2021, 2021, Online Only 


\section{International Conference on Space Optics-ICSO 2020}

Virtual Conference

30 March-2 April 2021

Edited by Bruno Cugny, Zoran Sodnik, and Nikos Karafolas
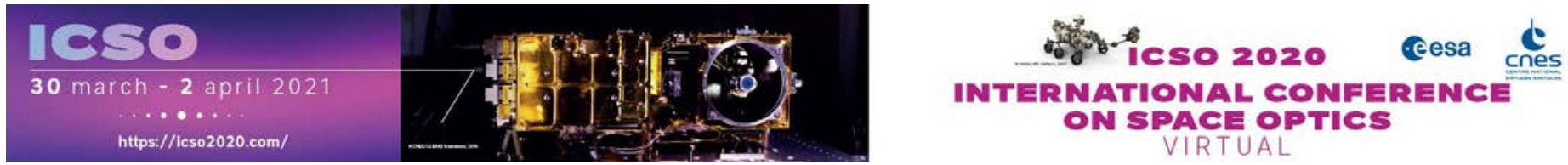

\section{Monitoring of JUICE Optical Fibers During Thermal Cycles Keeping the Optical Connectors at Different Stable Temperatures in 3-Chambers Setup}

\section{Cesa isso procedings denes}




\title{
Monitoring of JUICE Optical Fibers During Thermal Cycles Keeping the Optical Connectors at Different Stable Temperatures in 3-Chambers Setup
}

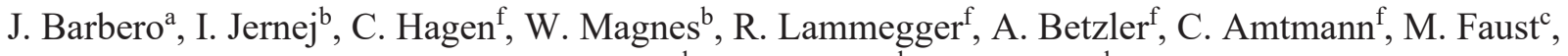 \\ A. Hauser ${ }^{c}$, T. Schirmann ${ }^{c}$, S. Mariojouls ${ }^{\mathrm{d}}$, A. Salomon ${ }^{\mathrm{d}}$, V. Lelievre ${ }^{\mathrm{d}}$, I. Torralba ${ }^{\mathrm{e}}$, I. McKenzie $^{\mathrm{e}}$ \\ a ALTER TECHNOLOGY, C/ La Majada 328760 Tres Cantos - Madrid, Spain \\ ${ }^{\mathrm{b}}$ Space Research Institute of the Austrian Academy of Sciences (IWF), Schmiedlstrasse 6 \\ A-8042 Graz, Austria \\ c AIRBUS Friedrichshafen Claude-Dornier-Straße, 88090 Immenstaad am Bodensee, Germany \\ d AIRBUS 31 Rue des Cosmonautes, 31400 Toulouse, France \\ ${ }^{\text {e }}$ ESA ESTEC, Keplerlaan 1, 2200 AG Noordwijk, Nederland \\ ${ }^{\mathrm{f}}$ Institute of Experimental Physics, Graz University of Technology (TUG), Petersgasse 16, A-8010 \\ Graz, Austria
}

\begin{abstract}
Two types of multimode fibers $(50 \mu \mathrm{m}$ and $400 \mu \mathrm{m})$ are going to be used for the scalar sensor of the JUICE (Jupiter Icy Moon Explorer program) magnetometer. This optical sensor will be placed at the end of a boom and these multimode fibers will be used to transmit modulated laser light through the sensor, the light source and the detector electronics being located within the spaceship. The fibers will be exposed to very low temperatures while the optical connectors will be more protected. The simulation of the optical budget did not allow to assure that the optical power transmitted through the fibers would be $\mathrm{OK}$ within the entire thermal range. A 3-chambers thermal cycling test was proposed to thermally cycle in a synchronized way to different temperature plateaus, both high and low, while monitoring the transmitted optical power. Some pieces of fibers and mating connectors were stabilized to one temperature while others were at other values. The temperature ranges for each chamber were: $-190^{\circ} \mathrm{C}$ to $120^{\circ} \mathrm{C}$ for one chamber, $-160^{\circ} \mathrm{C}$ to $100^{\circ} \mathrm{C}$ for the second one and $-80^{\circ} \mathrm{C}$ to $+45^{\circ} \mathrm{C}$ for the third one. The light source used for the test was developed by the institute of experimental physics at TUG Graz using exactly the same lasers that will be used for JUICE. The stability of the setup was assured using a reference path. This paper presents the main challenges for this test and the results obtained.
\end{abstract}

Keywords: Optic, fiber, jacket, connector, FC/APC, space.

\section{INTRODUCTION}

In May 2022, JUICE (JUpiter ICy moons Explorer) will begin a 7.6 year cruise to Jupiter to spend three and a half years in the Jovian system. Its main mission will be to explore the huge planet's three largest icy moons, Europa, Ganymede and Callist, in the hope of determining whether life is possible on these dwarf planets. One of the instruments that JUICE will carry is a Magnetometer that will be deployed with a 10.5 boom to keep it clear of the main body of the spacecraft, allowing to make measurements clear of any magnetic interference. Its goal is to measure Jupiter's magnetic field, its interaction with the internal magnetic field of Ganymede, and to study subsurface oceans of the icy moons. The data from and to the magnetometer will be sent using optical fibres travelling from the relatively protected ambient of the core of the ship to the boom. This structure will lead to a unique thermal profile of the fibers and optical connectors involved. A complex test with three coupled climatic chambers was proposed to thermally cycle the fibers and the connectors (FC/APC). The temperature that each pair of these connectors will be exposed during the mission will be significally different. The modelling of such a setup had never been verified and it was decided to actually test with the real expected temperature profile (including some margins). The rate and the temperature of each chambers was controlled independently to allow the simultaneous stabilization of the three chambers.

For a detailed description of the magnetometer system check the ICSO2020 paper Paper-0229-Irmgard JERNEJ. The following image (from https://www.esa.int/ESA_Multimedia/Images/2019/03/Juice_s_magnetometer_boom) shows the boom for JUICE. 


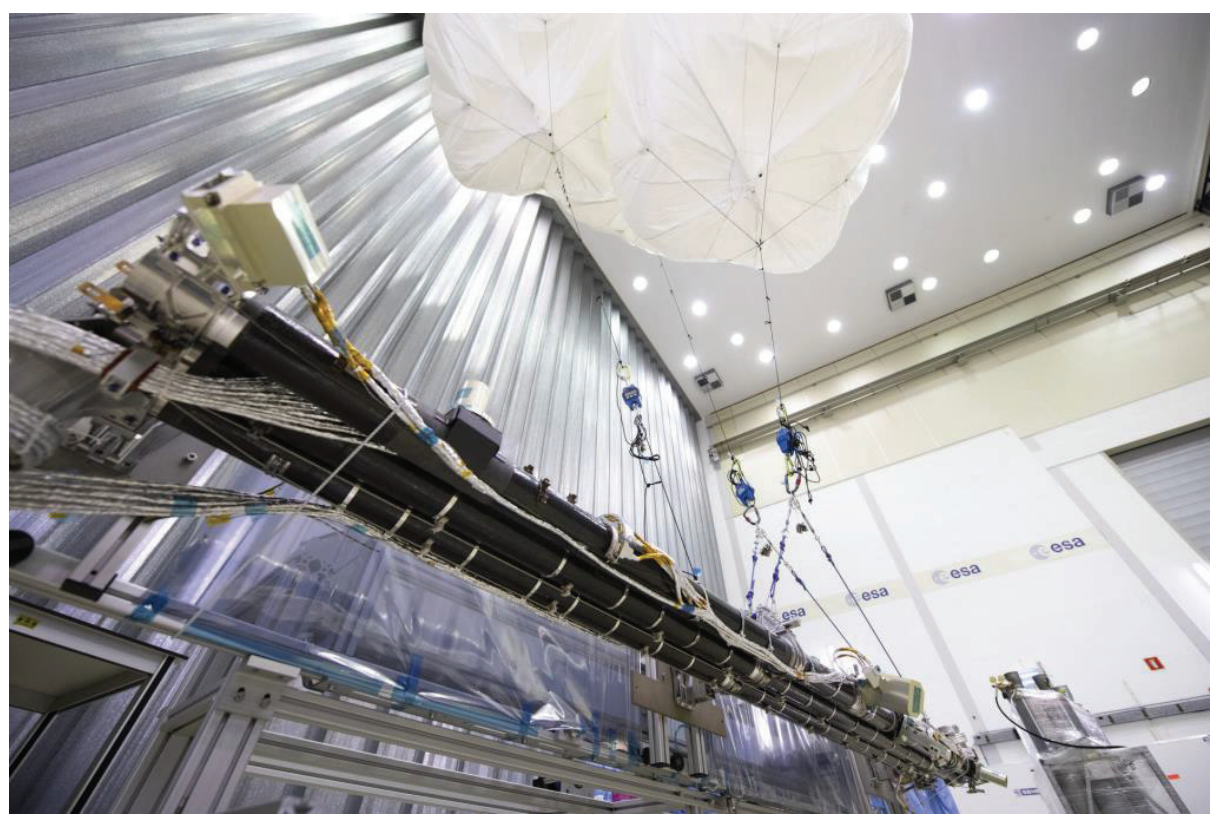

\section{TEST SETUP}

Several geometries for the placement of the samples were considered. The main limitations were related to the position of the holes to pass the fibers. Each chamber has a lateral hole normally used for access and some of the doors were also adapted to allow connecting them. The same stable light source used by IWF/TUG for the magnetometer was used during the test. The optical power of each of the paths was monitored with independent photodiodes read with a swiching matrix.

The following picture shows a top view of the 3-chambers configuration used during the thermal cycling test.

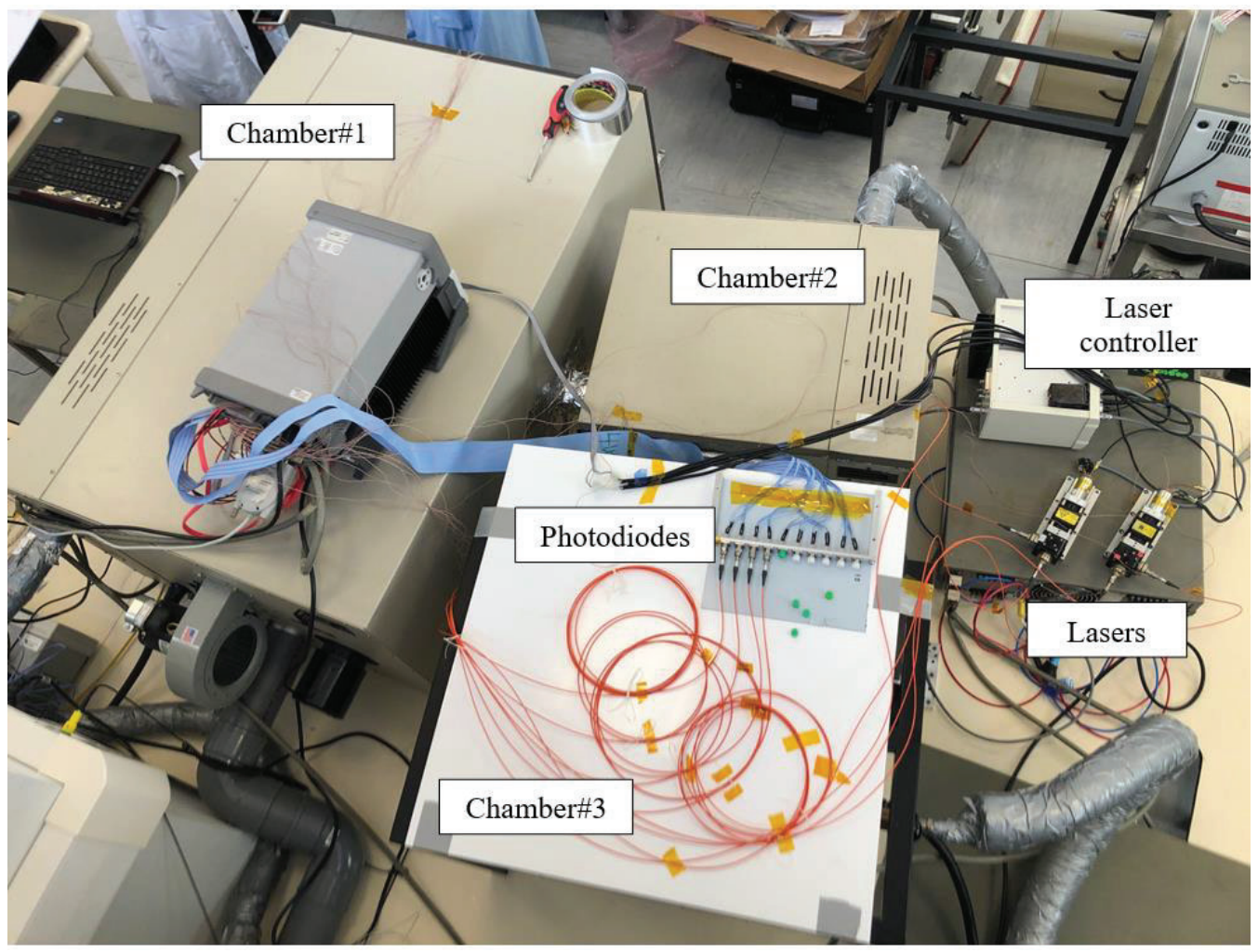


The following drawing shows the location for the thermocouples for the complete test and the path followed by each fiber to simulate the thermal ambient of the fibres following the boom. The minimum temperature of each chamber in indicated for identification.

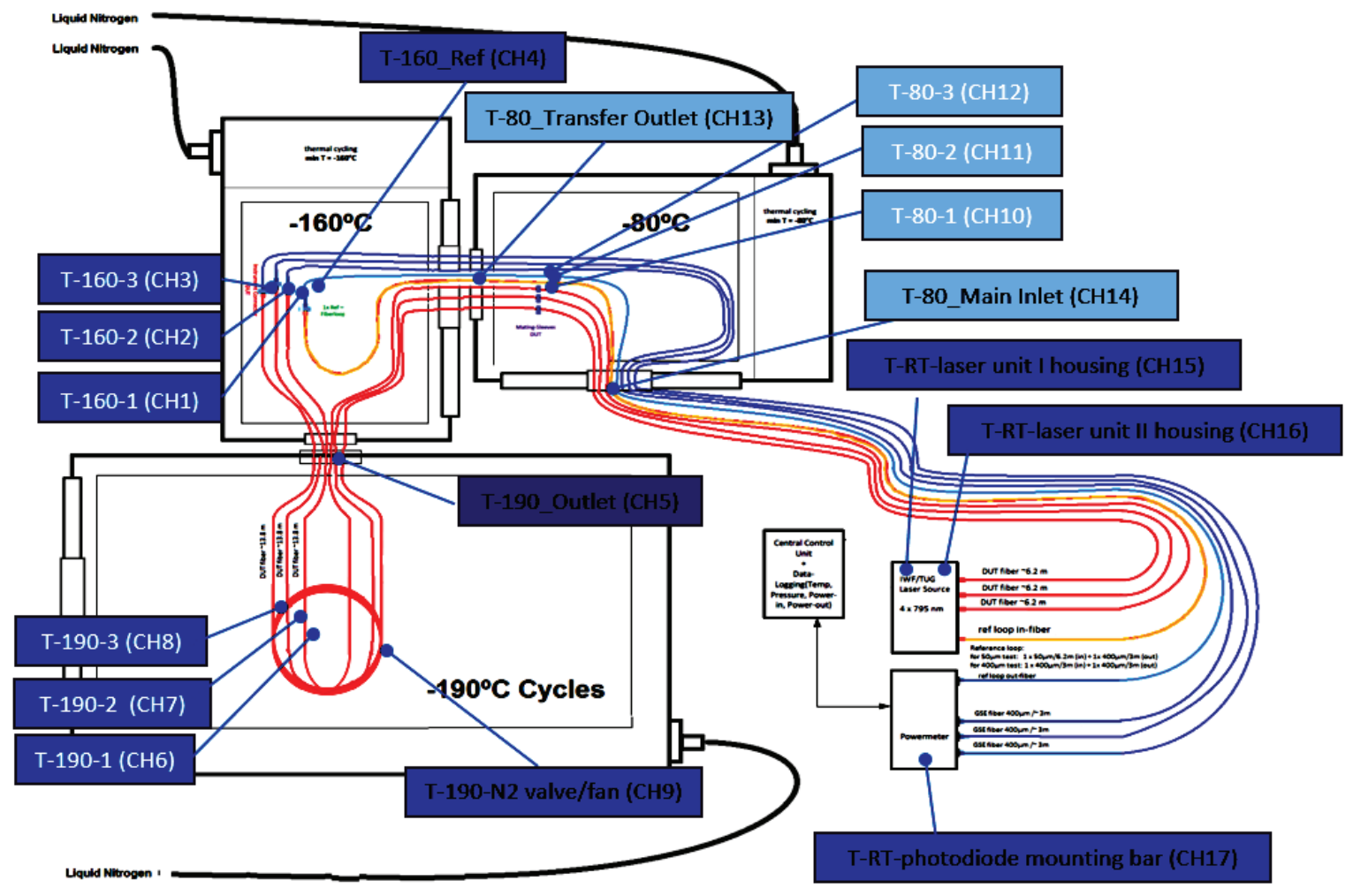

\section{TEST SEQUENCE}

The test sequence applied was the following:

- $\quad$ Placement of the samples in the chambers (done by IWF+TUG).

- Validation of the stability of the monitoring of optical power through the fibre paths at room temperature for 10 hours.

- $\quad$ First cycle with the following characteristics:

- Chamber\#1:

- Temp rate: $5^{\circ} \mathrm{C} / \mathrm{min}$

- High Temp: $120^{\circ} \mathrm{C}$ with minimum dwell time 10 minutes

- Low Temp step1: $-160^{\circ} \mathrm{C}$ with minimum dwell time 10 minutes

- Low Temp step2: $-170^{\circ} \mathrm{C}$ with minimum dwell time 10 minutes

- Low Temp step3: $-180^{\circ} \mathrm{C}$ with minimum dwell time 10 minutes

- Low Temp step4: $-190^{\circ} \mathrm{C}$ with minimum dwell time 10 minutes

- Chamber\#2:

- Temp rate: adjusted to reach the stabilization at the same time than chamber\#1

- High Temp: $100^{\circ} \mathrm{C}$ with chamber\#1 high temp dwell time

- Low Temp: $-160^{\circ} \mathrm{C}$ with total time chamber\#1 dwell time

- Chamber\#3:

- Temp rate: adjusted to reach the stabilization at the same time than chamber\#1

- High Temp: $45^{\circ} \mathrm{C}$ with chamber\#1 high temp dwell time

- Low Temp: $-80^{\circ} \mathrm{C}$ with total time chamber\#1 dwell time

- 48 cycles with the following characteristics:

- Chamber\#1:

- Temp rate: $5^{\circ} \mathrm{C} / \mathrm{min}$ 
- High Temp: $120^{\circ} \mathrm{C}$ with minimum dwell time 10 minutes

- Chamber\#2:

- Low Temp step1: $-190^{\circ} \mathrm{C}$ with minimum dwell time 10 minutes

- Temp rate: adjusted to reach the stabilization at the same time than chamber\#1

- High Temp: $100^{\circ} \mathrm{C}$ with chamber\#1 high temp dwell time

- Low Temp: $-160^{\circ} \mathrm{C}$ with total time chamber\#1 dwell time

- Chamber\#3:

- Temp rate: adjusted to reach the stabilization at the same time than chamber\#1

- High Temp: $45^{\circ} \mathrm{C}$ with chamber\#1 high temp dwell time

- Low Temp: $-80^{\circ} \mathrm{C}$ with total time chamber\#1 dwell time

- Final cycle with the following characteristics:

- Stabilization at room temperature for minimum 900 minutes.

- Chamber\#1:

- Temp rate: $5^{\circ} \mathrm{C} / \mathrm{min}$

- High Temp: $120^{\circ} \mathrm{C}$ with minimum dwell time 10 minutes

- Low Temp step $1:-160^{\circ} \mathrm{C}$ with minimum dwell time 10 minutes

- Low Temp step2: $-170^{\circ} \mathrm{C}$ with minimum dwell time 10 minutes

- Low Temp step3: $-180^{\circ} \mathrm{C}$ with minimum dwell time 10 minutes

- Low Temp step4: $-190^{\circ} \mathrm{C}$ with minimum dwell time 10 minutes

- Chamber\#2:

- Temp rate: adjusted to reach the stabilization at the same time than chamber\#1

- High Temp: $100^{\circ} \mathrm{C}$ with chamber\#1 high temp dwell time

- Low Temp: $-160^{\circ} \mathrm{C}$ with total time chamber\#1 dwell time

○ Chamber\#3:

- Temp rate: adjusted to reach the stabilization at the same time than chamber\#1

- High Temp: $45^{\circ} \mathrm{C}$ with chamber\#1 high temp dwell time

- Low Temp: $-80^{\circ} \mathrm{C}$ with total time chamber\#1 dwell time

\section{TEST RESULTS}

\section{1 $400 \mu \mathrm{m}$ MM Fibres test.}

The following picture shows the complete monitored data during the $400 \mu \mathrm{m}$ MM fibers test.

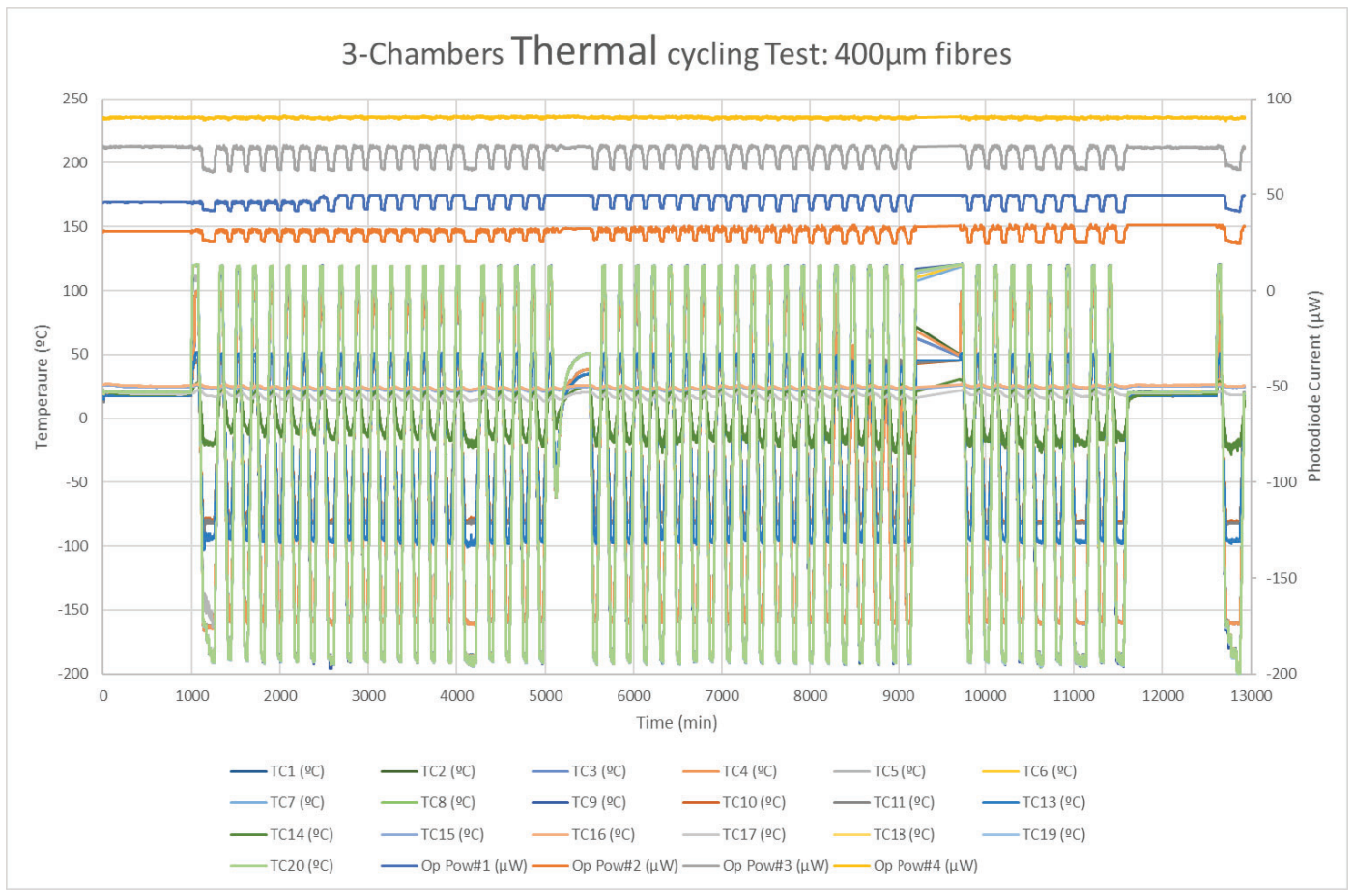


- The 4 top graphs are the photodiode current monitored. The yellow line is the reference path.

- The liquid nitrogen deposit was empty after 5100 minutes (the night of Sunday to Monday) and it was filled again on Monday morning.

- The monitoring of the test as well as the temperature variation programming was stopped after 9300minutes. This was related to a problem detected in chamber\#2 that cut the breaker switch associated to this chamber. After unplugging and plugging this chamber it started running again. This chamber was changed for the next test of the $50 \mu \mathrm{m}$ fibres.

The following picture shows a initial detail of the first cycles

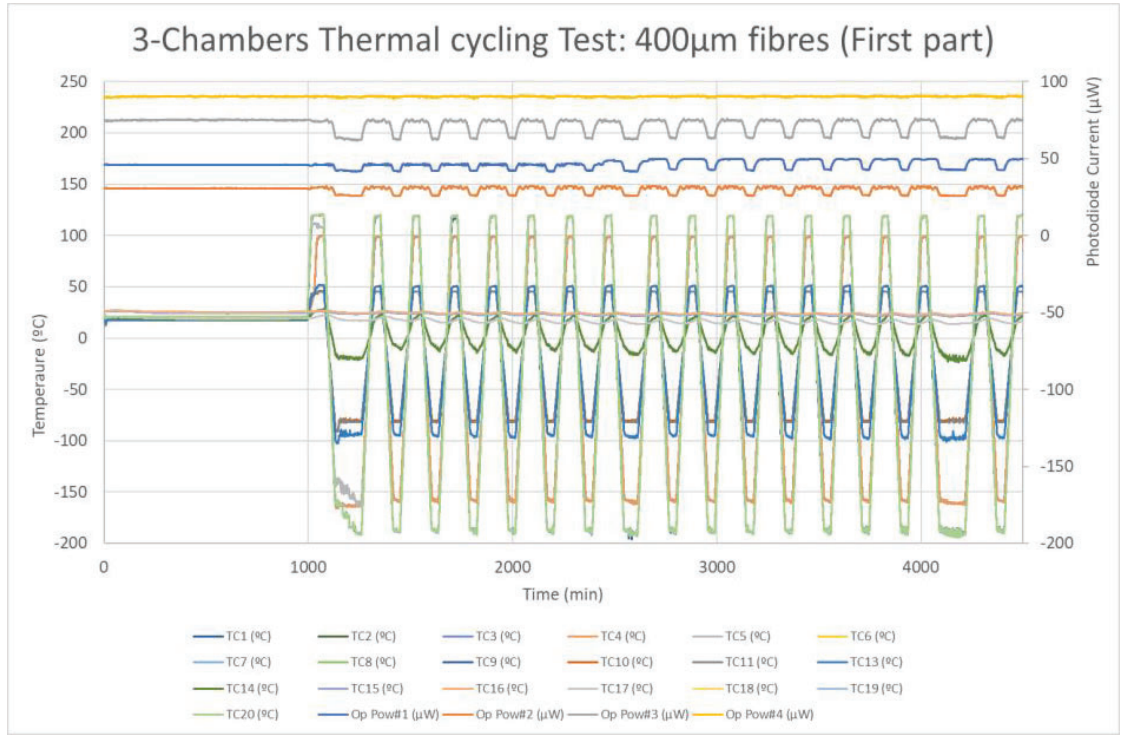

- First cycle had several steps during the cooling of the chamber\#1

- Cycle \#8 and particularly cycle \#16 have longer low temperature stabilizations. This was related to variations of the monitored temperature that fell out of the stabilization criteria leading to longer time needed to fulfil it.

The following picture shows a detail of the first cycle with several steps during the cooling of the chamber\#1 


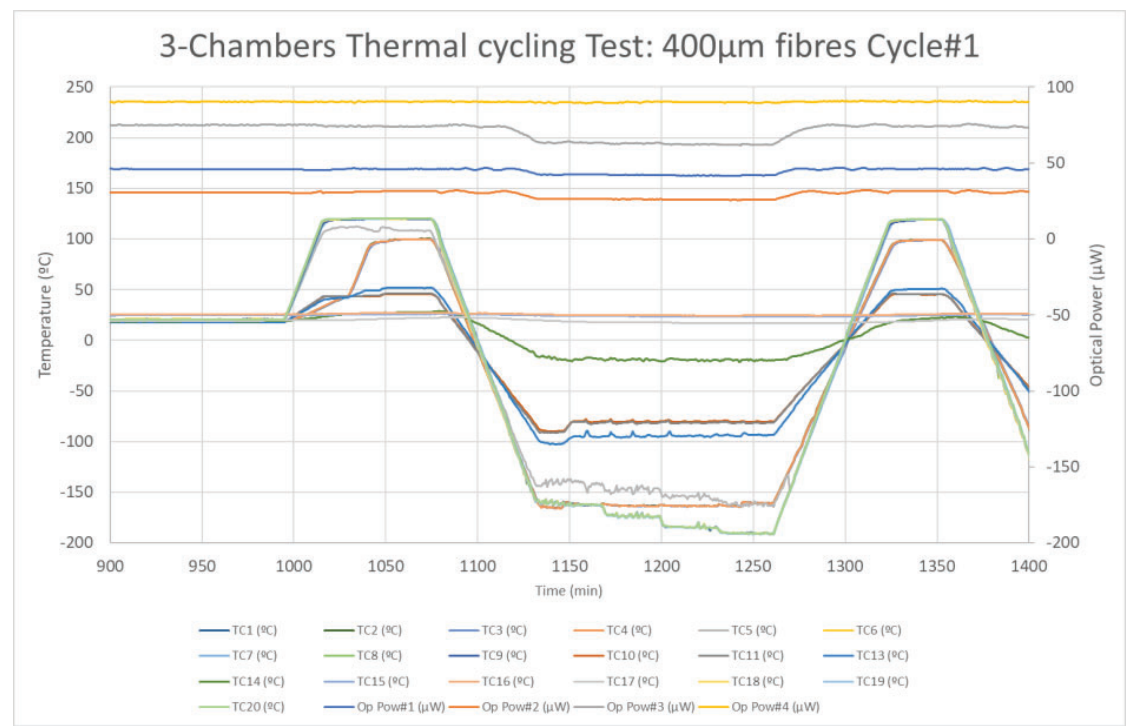

Proc. of SPIE Vol. 11852 118522S-7 


\section{$4.250 \mu \mathrm{m}$ MM Fibres test.}

The following picture shows the complete monitored data during the $50 \mu \mathrm{m} \mathrm{MM}$ fibres test.

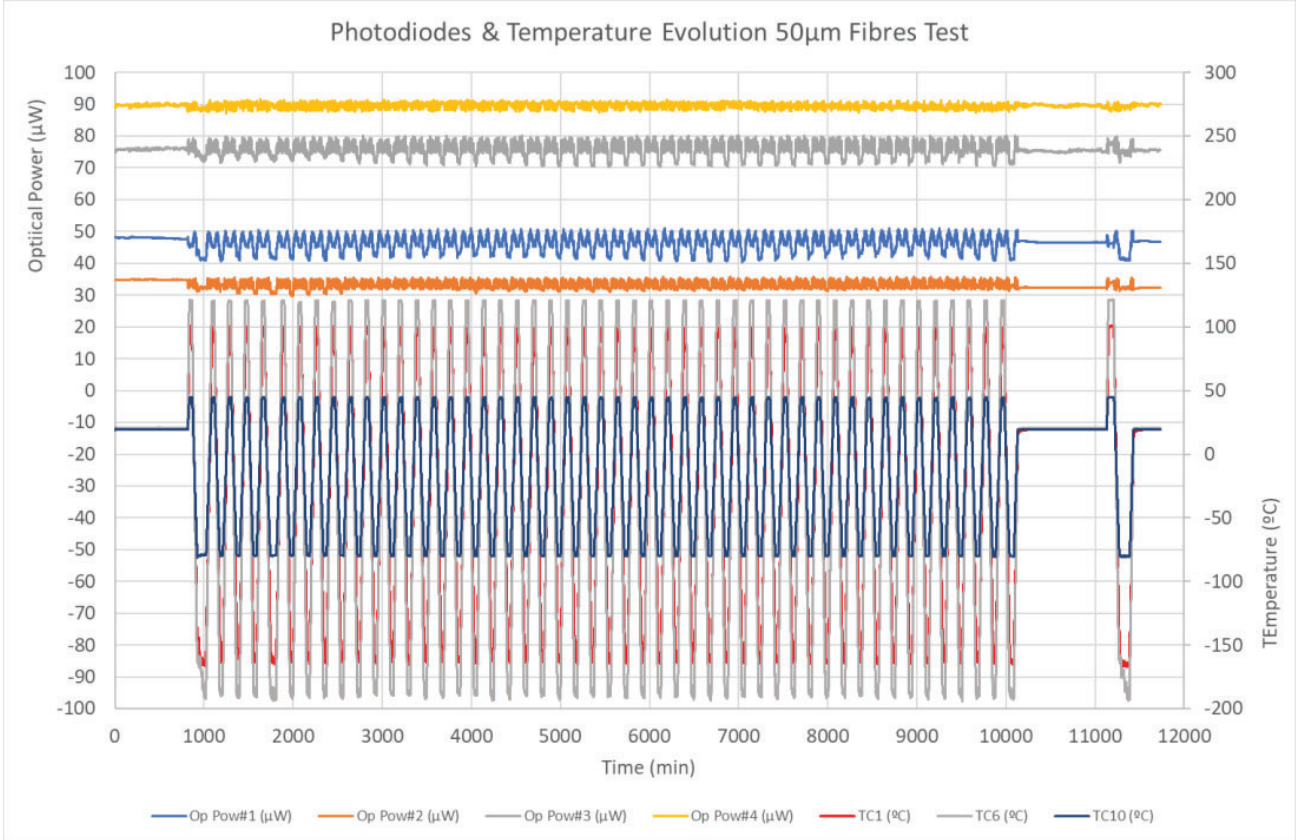

The 4 top graphs are the photodiode current monitored. The yellow line is the reference path.

The following picture shows a detail of the initial cycles.

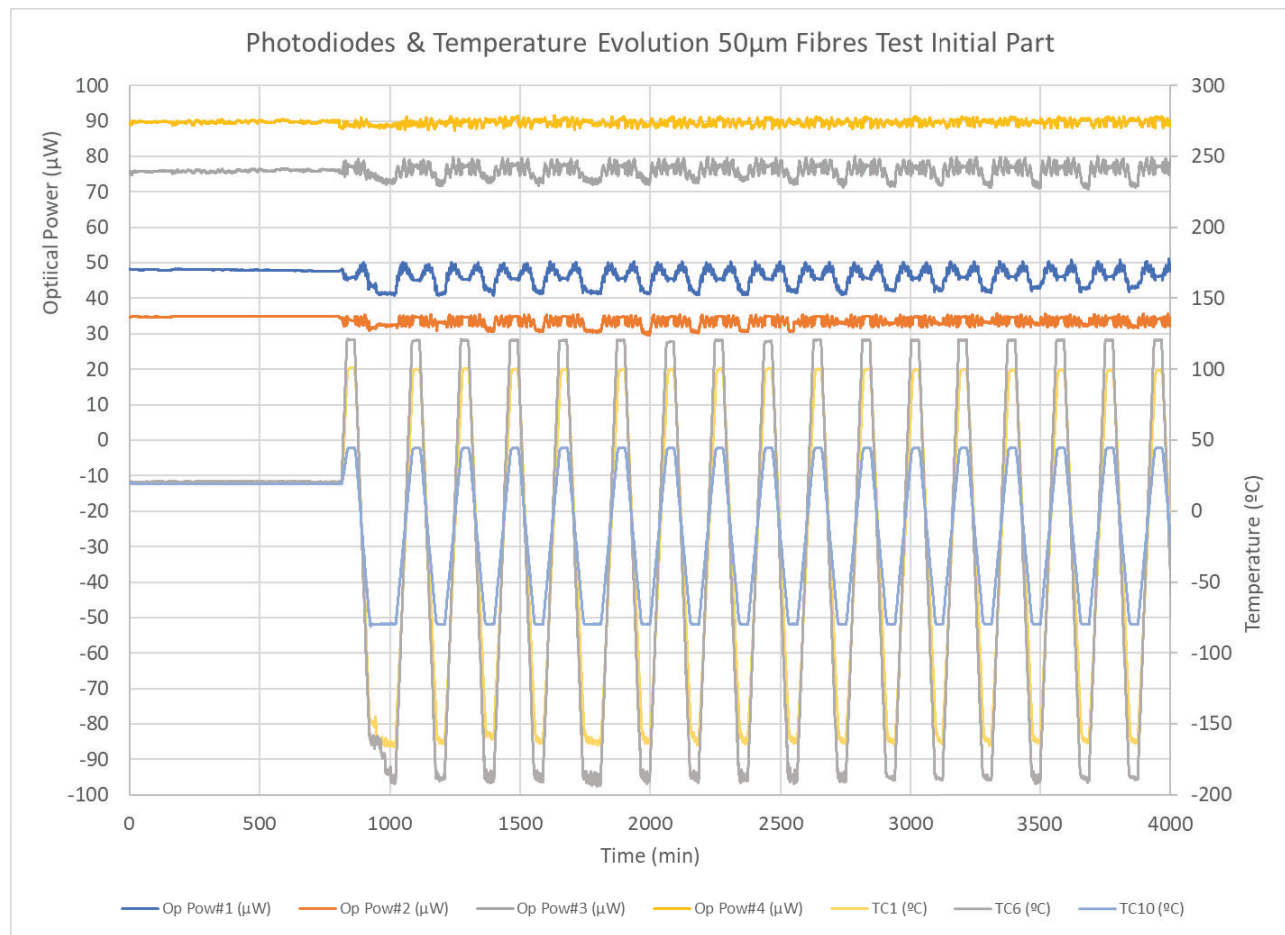

The first cycle had several steps during the cooling of the chamber\#1 
The following picture shows only the photodiode monitored optical power for each fibre. The highest monitored optical power is the reference path. The other three monitored photodiodes correspond to each of the fibre paths.

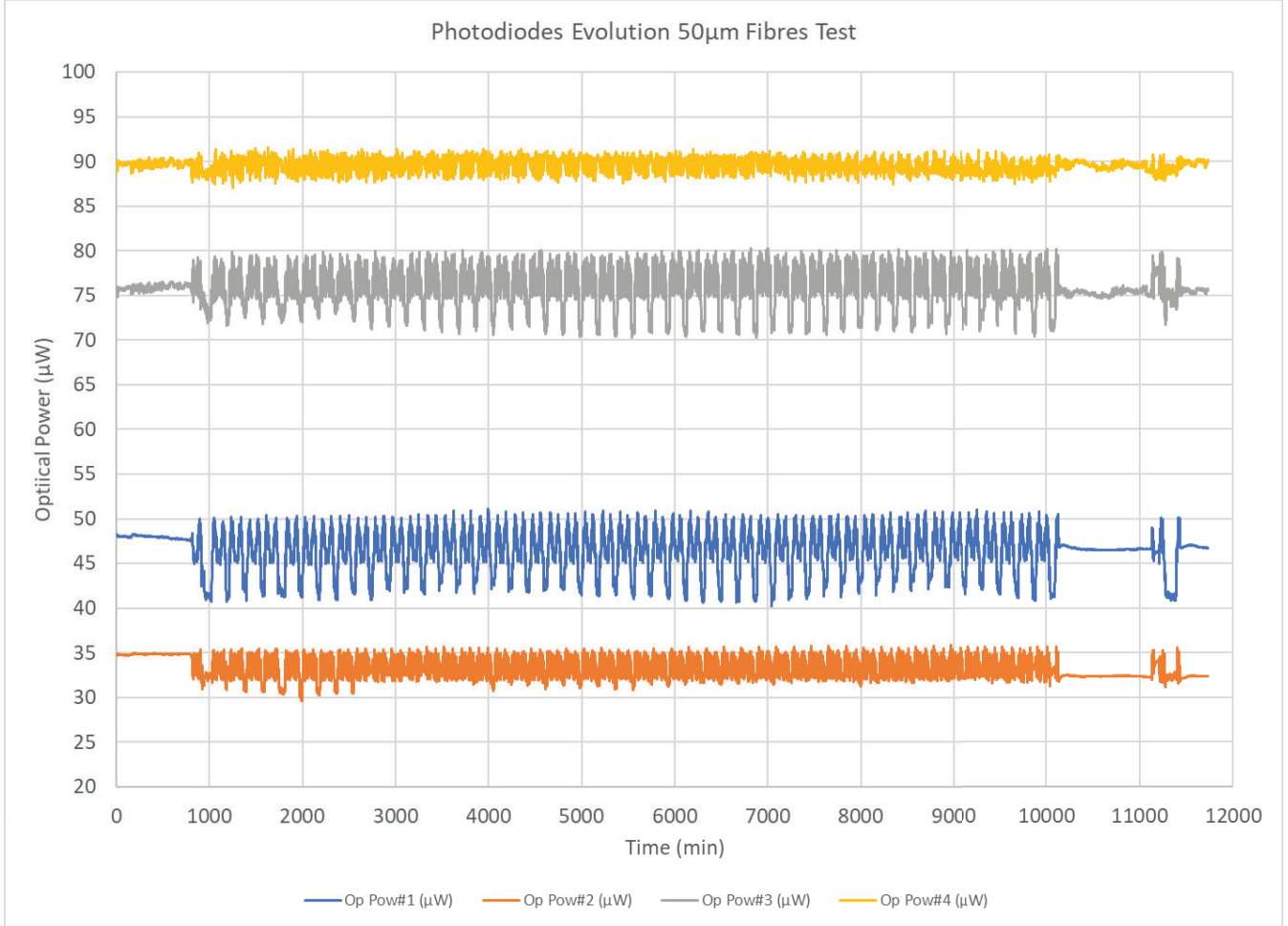

The following picture shows the first cycle monitored temperature and optical power.

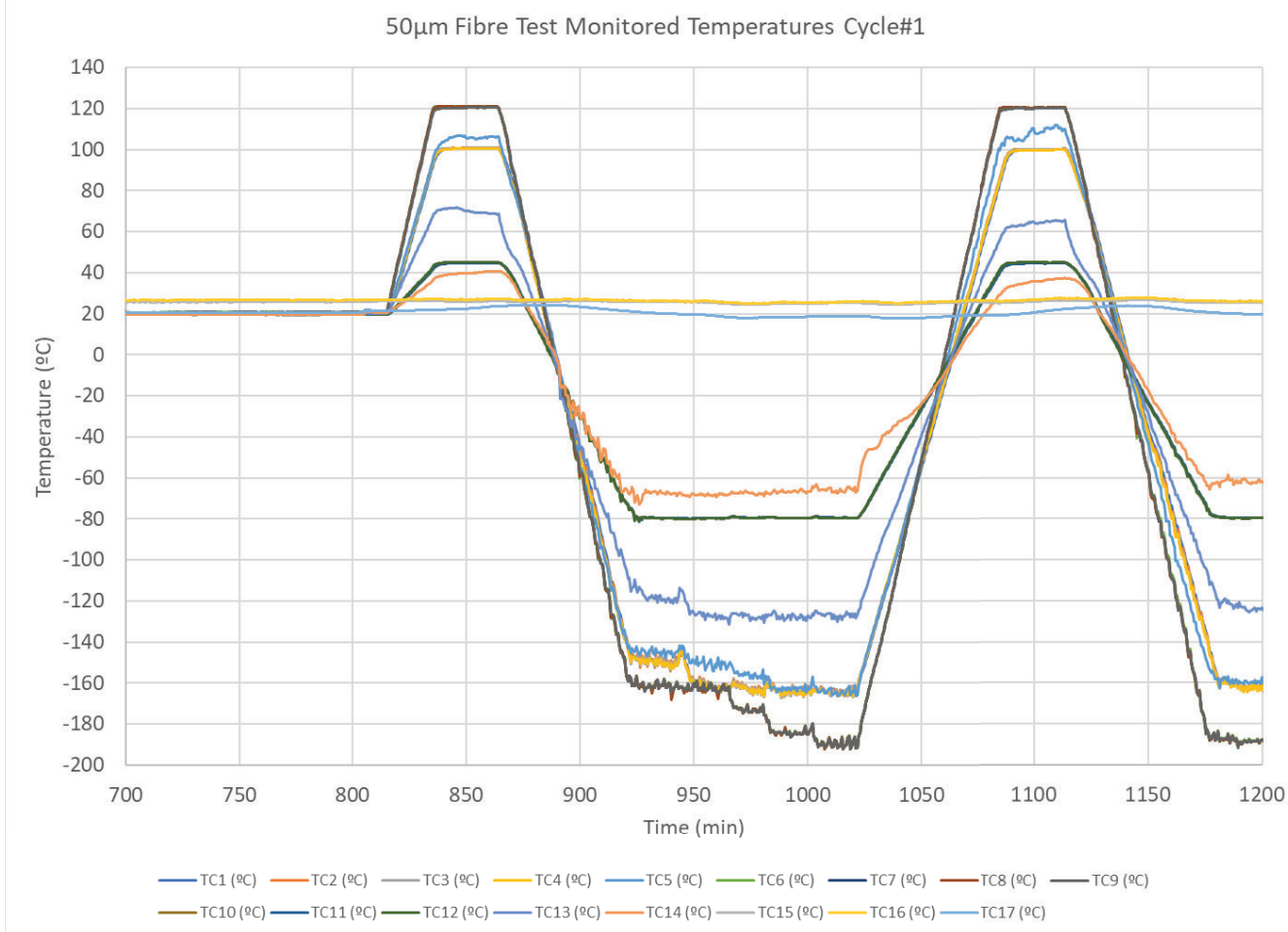

Proc. of SPIE Vol. 11852 118522S-9 


\section{NUMERICAL RESULTS}

A numerical comparison of the data at stabilized temperatures is given on the following tables:

The following tables present the results for the $400 \mu \mathrm{m}$ fibres:

\begin{tabular}{|c|c|c|c|c|c|c|c|c|c|}
\cline { 2 - 12 } \multicolumn{1}{c|}{} & \multicolumn{3}{c|}{ Initial Cycle Op Power $(\mu \mathrm{W})$} & \multicolumn{2}{c|}{ Final Op Power $(\mu \mathrm{W})$} & \multicolumn{3}{c|}{ Variation $(\%)$} \\
\hline Condition & $\begin{array}{c}\text { Room } \\
\text { Temp }\end{array}$ & $\begin{array}{c}\text { High } \\
\text { Temp }\end{array}$ & $\begin{array}{c}\text { Low } \\
\text { Temp }\end{array}$ & $\begin{array}{c}\text { Room } \\
\text { Temp }\end{array}$ & $\begin{array}{c}\text { High } \\
\text { Temp }\end{array}$ & $\begin{array}{c}\text { Low } \\
\text { Temp }\end{array}$ & $\begin{array}{c}\text { Room } \\
\text { Temp }\end{array}$ & $\begin{array}{c}\text { High } \\
\text { Temp }\end{array}$ & $\begin{array}{c}\text { Low } \\
\text { Temp }\end{array}$ \\
\hline Fiber\#1 & 46.0 & 46.0 & 41.9 & 49.3 & 49.3 & 41.4 & 7.2 & 7.2 & -1.2 \\
\hline Fiber\#2 & 30.8 & 31.7 & 25.8 & 33.8 & 32.5 & 25.0 & 9.7 & 2.5 & -3.1 \\
\hline Fiber\#3 & 75.1 & 74.1 & 62.2 & 74.6 & 75.5 & 62.9 & -0.7 & 1.9 & 1.1 \\
\hline Ref fiber & 90.1 & 90.4 & 89.8 & 90.7 & 90.4 & 89.7 & 0.7 & 0.1 & -0.1 \\
\hline
\end{tabular}

\begin{tabular}{|c|c|c|c|c|c|c|c|c|c|}
\cline { 2 - 11 } \multicolumn{1}{c|}{} & \multicolumn{3}{c|}{ Initial Cycle Op Power $(\mathrm{dBm})$} & \multicolumn{2}{c|}{ Final Op Power $(\mathrm{dBm})$} & \multicolumn{4}{c|}{ Variation $(\mathrm{dB})$} \\
\hline \multirow{2}{*}{ Condition } & $\begin{array}{c}\text { Room } \\
\text { Temp }\end{array}$ & $\begin{array}{c}\text { High } \\
\text { Temp }\end{array}$ & $\begin{array}{c}\text { Low } \\
\text { Temp }\end{array}$ & $\begin{array}{c}\text { Room } \\
\text { Temp }\end{array}$ & $\begin{array}{c}\text { High } \\
\text { Temp }\end{array}$ & $\begin{array}{c}\text { Low } \\
\text { Temp }\end{array}$ & $\begin{array}{c}\text { Room } \\
\text { Temp }\end{array}$ & $\begin{array}{c}\text { High } \\
\text { Temp }\end{array}$ & $\begin{array}{c}\text { Low } \\
\text { Temp }\end{array}$ \\
\hline Fiber\#1 & -13.37 & -13.37 & -13.78 & -13.07 & -13.07 & -13.83 & 0.30 & 0.30 & -0.05 \\
\hline Fiber\#2 & -15.11 & -14.99 & -15.88 & -14.71 & -14.88 & -16.02 & 0.40 & 0.11 & -0.14 \\
\hline Fiber\#3 & -11.24 & -11.30 & -12.06 & -11.27 & -11.22 & -12.01 & -0.03 & 0.08 & 0.05 \\
\hline Ref fiber & -10.45 & -10.44 & -10.47 & -10.42 & -10.43 & -10.47 & 0.03 & 0.00 & 0.00 \\
\hline
\end{tabular}

The following tables present the results for the $50 \mu \mathrm{m}$ fibres:

\begin{tabular}{|c|c|c|c|c|c|c|c|c|c|}
\cline { 2 - 11 } \multicolumn{1}{c|}{} & \multicolumn{2}{c|}{ Initial Cycle Op Power $(\mu \mathrm{W})$} & \multicolumn{2}{c|}{ Final Op Power $(\mu \mathrm{W})$} & \multicolumn{4}{c|}{ Variation $(\%)$} \\
\hline Condition & $\begin{array}{c}\text { Room } \\
\text { Temp }\end{array}$ & $\begin{array}{c}\text { High } \\
\text { Temp }\end{array}$ & $\begin{array}{c}\text { Low } \\
\text { Temp }\end{array}$ & $\begin{array}{c}\text { Room } \\
\text { Temp }\end{array}$ & $\begin{array}{c}\text { High } \\
\text { Temp }\end{array}$ & $\begin{array}{c}\text { Low } \\
\text { Temp }\end{array}$ & $\begin{array}{c}\text { Room } \\
\text { Temp }\end{array}$ & $\begin{array}{c}\text { High } \\
\text { Temp }\end{array}$ & $\begin{array}{c}\text { Low } \\
\text { Temp }\end{array}$ \\
\hline Fiber\#1 & 48.00 & 45.98 & 41.49 & 46.76 & 46.32 & 41.19 & -2.6 & 0.7 & -0.7 \\
\hline Fiber\#2 & 34.85 & 33.57 & 32.63 & 32.34 & 34.22 & 32.53 & -7.2 & 1.9 & -0.3 \\
\hline Fiber\#3 & 76.28 & 77.26 & 72.53 & 75.75 & 78.05 & 74.68 & -0.7 & 1.0 & 3.0 \\
\hline Ref fiber & 90.06 & 89.04 & 88.42 & 90.09 & 88.75 & 89.20 & 0.0 & -0.3 & 0.9 \\
\hline
\end{tabular}

\begin{tabular}{|c|c|c|c|c|c|c|c|c|c|}
\cline { 2 - 10 } \multicolumn{1}{c|}{} & \multicolumn{2}{c|}{ Initial Cycle Op Power $(\mathrm{dBm})$} & \multicolumn{2}{c|}{ Final Op Power $(\mathrm{dBm})$} & \multicolumn{4}{c|}{ Variation $(\mathrm{dB})$} \\
\hline Condition & $\begin{array}{c}\text { Room } \\
\text { Temp }\end{array}$ & $\begin{array}{c}\text { High } \\
\text { Temp }\end{array}$ & $\begin{array}{c}\text { Low } \\
\text { Temp }\end{array}$ & $\begin{array}{c}\text { Room } \\
\text { Temp }\end{array}$ & $\begin{array}{c}\text { High } \\
\text { Temp }\end{array}$ & $\begin{array}{c}\text { Low } \\
\text { Temp }\end{array}$ & $\begin{array}{c}\text { Room } \\
\text { Temp }\end{array}$ & $\begin{array}{c}\text { High } \\
\text { Temp }\end{array}$ & $\begin{array}{c}\text { Low } \\
\text { Temp }\end{array}$ \\
\hline Fiber\#1 & -13.19 & -13.37 & -13.82 & -13.30 & -13.34 & -13.85 & -0.11 & 0.03 & -0.03 \\
\hline Fiber\#2 & -14.58 & -14.74 & -14.86 & -14.90 & -14.66 & -14.88 & -0.32 & 0.08 & -0.01 \\
\hline Fiber\#3 & -11.18 & -11.12 & -11.39 & -11.21 & -11.08 & -11.27 & -0.03 & 0.04 & 0.13 \\
\hline Ref fiber & -10.45 & -10.50 & -10.53 & -10.45 & -10.52 & -10.50 & 0.00 & -0.01 & 0.04 \\
\hline
\end{tabular}

\section{CONCLUSION}

A complex thermal cycling test was necessary to test the fibers that are going to be used in the real scenario for the magnetometer of the JUICE Mission. The analysis of the results of the triple thermal test of both types of fibers show no measurable degradation. The preparation of the test was complex, but it allowed the validation of the test setup in an equivalent thermal scenario as the expected during the mission. The actual test setup, including the handling of the fibers and the connectorization was done by the staff of the Space Research Institute of the Austrian Academy of Sciences (IWF) and of the Technical University of Graz at ALTER premises. 